\title{
Experiências em Conservação e Educação Patrimonial no contexto de escavações arqueológicas
}

\author{
Carla Gibertoni Carneiro* \\ Silvia Cunha Lima**
}

É crescente o número de trabalhos relacionados à reflexão sobre o grande interesse que hoje desperta a busca pela aproximação do conhecimento produzido pela ciência arqueológica junto à sociedade e pela compreensão dos significados que essa aproximação proporciona.

Há uma conjuntura de fatores que configuram este contexto e é a partir desse universo de relações complexas e muitas vezes díspares, uma vez que envolve diferentes campos do conhecimento na trajetória das reflexões que balizam estas discussões, que alguns apontamentos serão aqui apresentados.

Os referenciais teórico-metodológicos adotados para a apresentação das reflexões propostas, bem como os que balizam o projeto que será aqui descrito advêm da arqueologia pública, musealização da arqueologia, conservação arqueológica e educação patrimonial.

A arqueologia pública é um ramo que ganha cada vez mais espaço e diferentes contornos no cerne da disciplina arqueológica. Há uma diversidade de aspectos que estão envolvidos na concepção deste termo, mas percebe-se uma convergência quanto à acepção de que este é um campo de atuação voltado às ações extramuros do universo acadêmico.

Acreditamos em uma dimensão pública da Arqueologia que não seja possibilitar ao público

$\left({ }^{*}\right)$ Museu de Arqueologia e Etnologia da Universidade de São Paulo. Educadora do Serviço Técnico de Musealização.cgiber@usp.br

$\left({ }^{* *}\right)$ Museu de Arqueologia e Etnologia da Universidade de São Paulo. Conservadora do Serviço Técnico de Curadoria.silviacl@usp.br a simples abertura ou contato com as áreas de pesquisa, para que as pessoas vejam o que os arqueólogos estão pesquisando e como; e sim como a proposição de um diálogo sobre os dados que estão sendo produzidos e em que medida essas informações vão interferir, refletir na vida dessas pessoas.

É amplo o conjunto de características que aproximam a arqueologia dos museus. Esta, enquanto ciência, tem sua gênese no universo museológico, base que configurou, no início, a partir da lógica dessas instituições, a forma como as pesquisas arqueológicas eram desenvolvidas, bem como a forma de constituição das coleções. Após um período de ruptura, em que se buscaram outros parâmetros (universidades) para o desenvolvimento das pesquisas arqueológicas, na atualidade é visível um movimento de reaproximação, relacionado, em muitos aspectos, ao modelo previsto pela legislação para o gerenciamento do patrimônio arqueológico, principalmente o contexto da arqueologia empresarial.

Também no contexto dos museus surge o conceito de preservação dos acervos constituídos. Inicialmente, no período entre e pós as duas Guerras Mundiais, formam-se laboratórios de conservação e restauro principalmente para lidar com os danos provocados pelos deslocamentos e armazenagem inadequadas dos acervos. Com o desenvolvimento de técnicas científicas e novos materiais, ainda no âmbito dos museus, a conservação aprofunda-se na diversidade e especificidade dos materiais compósitos das coleções e os diferentes agentes de degradação dos mesmos, ampliando sua atuação "restauradora" de processos já desencadeados, para uma ação mais abrangente que envolve não somente 
Experiências em Conservação e Educação Patrimonial no contexto de escavações arqueológicas. Revista do Museu de Arqueologia e Etnologia, São Paulo, 18: 331-335, 2008.

os materiais isoladamente, mas também o pesquisador, o ambiente circundante (do contexto arqueológico à reserva técnica) e o conhecimento científico gerado por essas coleções (Braga 2003).

Da mesma forma que a arqueologia pública e a conservação arqueológica, a educação patrimonial apresenta-se de variadas formas: como metodologia, como campo de conhecimento, como parte da legislação vigente relacionada ao patrimônio arqueológico.

Na discussão pertinente às ações de educação patrimonial relacionadas à arqueologia é inegável a influência da legislação relativa à proteção do patrimônio arqueológico em âmbito nacional, principalmente depois da implantação da Portaria IPHAN no 230, de 17 de dezembro de 2002, que sinaliza os procedimentos a serem desenvolvidos nos projetos de arqueologia para obtenção de licença para pesquisa. A partir desse período é notável o crescimento de trabalhos voltados à divulgação do conhecimento produzido a partir das pesquisas arqueológicas à sociedade.

Nesse novo contexto que se constitui cabe realizarmos alguns questionamentos em relação à natureza das ações propostas: quanto o patrimônio arqueológico está, de fato, no cerne dos trabalhos propostos, sendo o ponto de partida para a produção, conservação e comunicação do conhecimento em arqueologia? Qual a formação (acadêmica/profissional) das equipes proponentes e executoras dessas ações? Quais os parâmetros teóricos e metodológicos que estão na base desses projetos? Há preocupação em relação aos desdobramentos das ações desenvolvidas?

Consideramos fundamental para o desenvolvimento de ações desta natureza a presença de profissionais qualificados tanto do ponto de vista de ter um conhecimento aprofundado em arqueologia, quanto em relação a outros campos do conhecimento voltados à conservação do patrimônio e à comunicação deste conhecimento, como por exemplo, a museologia e a educação.

Esta defesa vem respaldada numa visão de preservação do patrimônio arqueológico compartilhada, na qual a ação conjunta dos profissionais que viabilizam estas ações permita: ao arqueólogo gerenciar a investigação e interpretação sobre os modos de vida das sociedades humanas ao longo de sua existência; ao conservador desenvolver critérios e métodos para preservar a materialidade e/ou as informações pertinentes ao registro arqueológico (base para o desenvolvimento dos estudos arqueológicos) às futuras gerações e ao educador comunicar e refletir sobre os elementos desse processo com os agentes do presente.

O educador tem o papel de um mediador, responsável por decodificar o conhecimento científico para comunicá-lo aos mais diversos públicos. Este processo de comunicação objetiva tornar compreensíveis as informações, reflexões inerentes a este conhecimento, constituindo-se em um novo conhecimento, que alia as informações sobre esses públicos (vivências, expectativas), as estratégias envolvidas nessa decodificação (processos comunicativos) e, a partir de processos avaliativos, novos direcionamentos. É de fato um campo de atuação e pesquisa, que exige formação direcionada e experiência como qualquer outro envolvimento profissional.

Acreditamos nesse processo em um sentido dialógico e dialético, ou seja, à medida que se desenvolvem ações junto aos mais diversos contextos culturais (diferentes visões de mundo, tensões, conflitos) podem estabelecer-se novos contornos e direcionamentos tanto para os processos comunicativos quanto, idealmente, para a produção do conhecimento, nesse caso específico, arqueológico. A ação educativa é vista, neste sentido, não como mera tradutora de conceitos e conteúdos científicos, mas na sua dimensão social e política, desempenhando o papel provocador de reflexões aprofundadas e críticas sobre a produção e socialização do conhecimento numa dimensão transformadora da realidade.

A conservação arqueológica é responsável por um conjunto de ações que visa minimizar a perda de informações que ocorre quando o processo de escavação separa o registro/vestígio do sítio de proveniência. Suas técnicas são aplicadas aos materiais escavados durante e imediatamente depois à sua exposição ao ar e ao contexto remanescente in situ. Esta é a conservação em campo, algumas vezes, com técnicas e 
ações distintas da conservação arqueológica em laboratório. Porém, enquanto os métodos de escavação e outras técnicas arqueológicas desenvolveram-se notavelmente nos últimos 50 anos, os standards de conservação de materiais arqueológicos em campo não têm, em geral, progredido da mesma forma.

O que pode realmente fazer um conservador na escavação, ainda é uma pergunta difícil de responder no âmbito nacional. Além das questões relacionadas à legislação desta profissão no país, talvez esta dificuldade derive justamente de não estarmos habituados com a figura do conservador envolvido nas atividades de campo. Ainda são relativamente desconhecidas as possibilidades de ação que representa esta participação, ou seja, questões relacionadas à conservação em campo são deixadas de lado, pois não costumam fazer parte dos problemas que devem ser gerenciados pelo arqueólogo. Pouco se questiona sobre o planejamento e realização da recuperação e transporte dos materiais ou os métodos de conservação do registro em seu contexto e a preservação dos sítios arqueológicos após a escavação, ou seja, muitas discussões serão necessárias, e muitas perguntas surgirão até compreendermos o papel da conservação arqueológica.

Com base nesse universo de reflexões, aqui brevemente sinalizado, é que apresentaremos, a seguir, um exemplo de ação educativa e conservação arqueológica desenvolvidas no contexto do sítio-escola, realizado em 2007, no município de Iranduba-AM, como uma etapa de pesquisa do Projeto Amazônia Central, coordenado pelo Prof. Dr. Eduardo Góes Neves, ${ }^{1}$ financiado pela Fapesp.

Foi a primeira experiência de realização concreta de ações educativas no contexto de pesquisa do Projeto Amazônica Central. Em anos anteriores, foram feitos contatos com a Secretaria de Educação, e ministrado um curso voltado a agentes multiplicadores no contexto do Programa de Educação Patrimonial -

(1) Integrante do corpo docente do Museu de Arqueologia e Etnologia/USP.
Gasoduto Coari-Manaus, que abrange a área do município de Iranduba-AM.

As ações educativas desenvolvidas nesta etapa foram direcionadas ao público escolar. $\mathrm{O}$ objetivo deste enfoque foi avaliar como os professores, que participaram do curso Arqueologia Amazônica no Contexto Educacional, ministrado no Município em 2006, abordaram as temáticas sugeridas relacionadas à arqueologia da região no contexto de sala de aula juntamente com seus alunos.

A proposta foi apresentada e acolhida pela Secretaria de Educação do Município e desenvolveu-se a partir das seguintes ações: atividade em sala de aula com os alunos para discutir temáticas relacionadas à arqueologia potencialmente já apresentadas pelos professores a partir do curso supracitado; visita com os alunos às áreas de escavação e visita com os alunos ao laboratório de conservação arqueológica. As atividades foram voltadas aos alunos do Ensino Fundamental, Médio e EJA.

O trabalho com os alunos em sala de aula teve como objetivo apresentar e discutir as principais questões levantadas / sugeridas pelas pesquisas arqueológicas da região. $\mathrm{O}$ contato foi iniciado a partir dos conhecimentos prévios dos alunos sobre arqueologia de um ponto de vista mais geral até chegar ao enfoque mais específico das pesquisas regionais. Esta conversa foi conduzida também a partir dos kits com material arqueológico que se encontram na Secretaria de Educação do Município. Este recurso foi um ponto de partida para sensibilizar os alunos quanto à importância do patrimônio arqueológico (como fonte) para a produção de conhecimento sobre a história regional e divulgação das pesquisas numa perspectiva educacional.

Os conceitos preliminarmente trabalhados em sala de aula foram aprofundados com a visita às áreas de escavação, no sítio arqueológico e ao laboratório de conservação arqueológica. $\mathrm{O}$ objetivo da visita foi apresentar concretamente como se desenvolve a pesquisa arqueológica.

No sítio arqueológico, além de discutir os métodos e técnicas de escavação, colocamos os alunos a par dos principais problemas de pesquisa levantados para esta área específica (Fig. 1); no laboratório, foram apresentados e 
Experiências em Conservação e Educação Patrimonial no contexto de escavações arqueológicas. Revista do Museu de Arqueologia e Etnologia, São Paulo, 18: 331-335, 2008.

discutidos os procedimentos adotados após a retirada do material arqueológico do local onde foi encontrado.

A experiência de montagem de um laboratório em campo foi fundamental para darmos início ao questionamento sobre o papel do conservador. Nesta primeira experiência, improvisamos o necessário para desenvolvermos nosso objetivo inicial de limpeza e análise preliminar do material cerâmico proveniente da escavação. Como na equipe contávamos com um topógrafo para o mapeamento dos limites do sítio arqueológico e numericamente seriam poucos participantes no laboratório, junto com o coordenador do projeto, decidimos que seria interessante trabalhar com o material proveniente da sondagem, almejando alcançarmos alguns resultados ainda durante o campo, que pudessem ser úteis para a interpretação do sítio (Fig. 2).

Devido ao contato com os laboratórios de arqueologia do MAE, percebíamos a necessidade de implementar novos métodos de limpeza do registro cerâmico que amenizassem a perda de informações, principalmente associadas aos tratamentos da superfície e decoração, decorrentes dos procedimentos tradicionais de lavagem da cerâmica adotada pelos arqueólogos.

Apesar de inicialmente termos encontrado certa desconfiança por parte de alguns participantes, foi possível através das atividades do laboratório em campo, demonstrar o potencial de diferentes métodos de limpeza e discutir sobre a adequação de cada um em relação às características específicas do material, após conversar sobre alguns parâmetros da conservação e da composição físico-química da cerâmica.

Ao término do sítio-escola de 2007, percebemos que algumas estratégias adotadas foram eficientes, como por exemplo, o rodízio dos participantes, a oportunidade de experimentarmos técnicas para uma melhor conservação do material desde sua remoção do campo e as discussões sobre critérios de conservação e sobre algumas características da cerâmica daquela região.

Embora embrionária esta experiência, que aliou ações de diferentes vertentes relativas à interpretação, preservação e comunicação do patrimônio arqueológico, sinalizou pers-

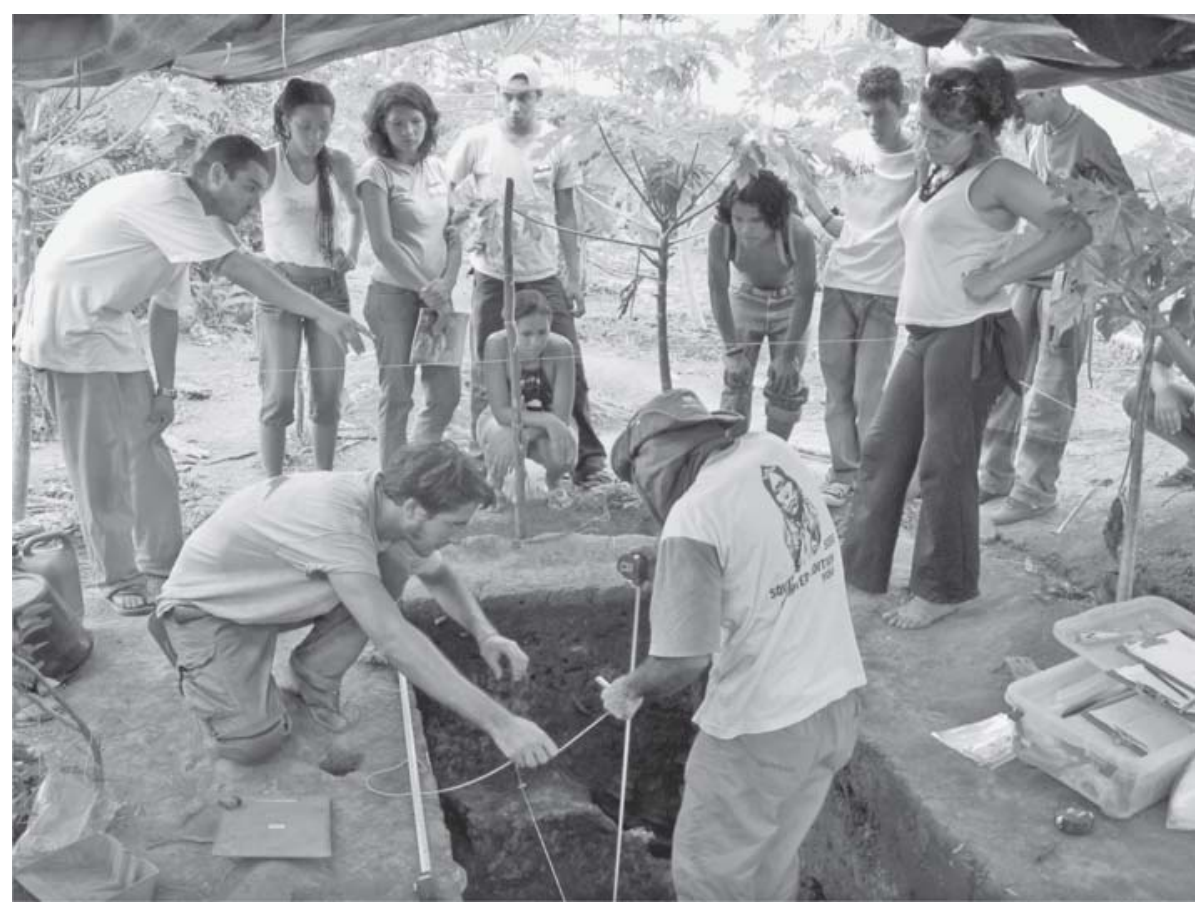

Fig. 1. Visita de alunos às áreas de escavação do sítio arqueológico Laguinho, em Iranduba-AM. 


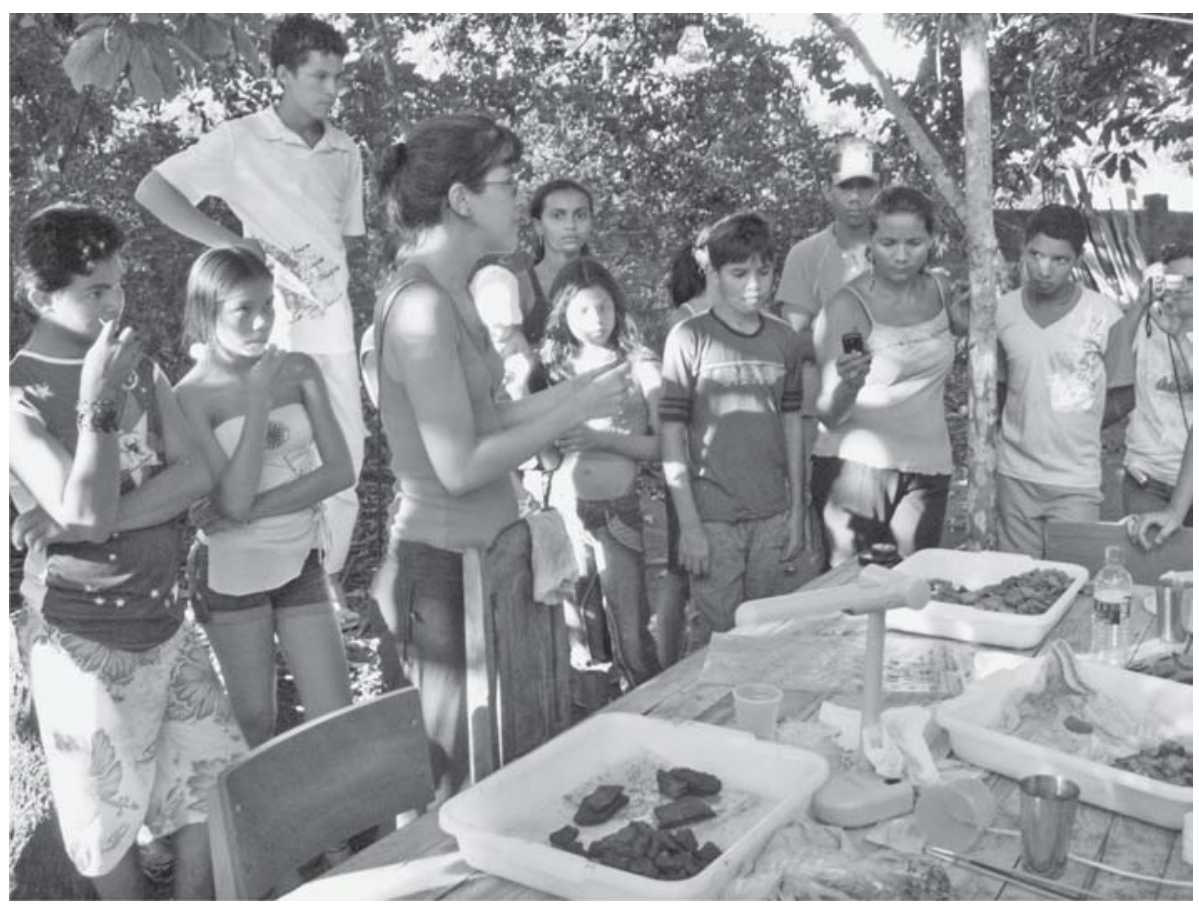

Fig. 2. Visita de alunos ao laboratório em campo, em Iranduba-AM.

pectivas muito positivas, uma vez que permitiu, durante a etapa de formação de futuros arqueólogos, evidenciar a importância de estudos e trabalhos interdisciplinares; desen- volveu a pesquisa arqueológica de maneira mais abrangente e iniciou um processo de comunicação sobre o papel da arqueologia na região junto à população local.

\section{Bibliografia e referência bibliográfica}

BRAGA, G.B.

2003 Conservação Preventiva: acondicionamento e armazenamento de acervos complexos em Reserva Técnica. Dissertação de Mestrado, Escola de Comunicação e Arte, Universidade de São Paulo, São Paulo.

BRUNO, M.C.O.

2001 Museologia: a luta pela perseguição ao abandono. Tese (Livre-Docência) - Museu de Arqueologia e Etnologia, Universidade de São Paulo, São Paulo.

\section{CONSERVATION}

2003 Getty Conservation Institute Newsletter, $18(1)$.

LIMA, T.A. (Org.)

2007 Patrimônio Arqueológico: o desafio da preservação. Revista do Patrimônio Histórico e Artístico Nacional. IPHAN: Brasília, 33.

PRICE, N.S.

1986 Scavo e Conservazione. In: La Conservazione sullo Scavo Archeologico. Roma, ICCROM: 8-19. 